\title{
Image of the month: Chest pain after cocaine use
}

\author{
Authors: Richard Bond, ${ }^{A}$ Edward Duncan ${ }^{B}$ and Angus Nightingale ${ }^{C}$
}

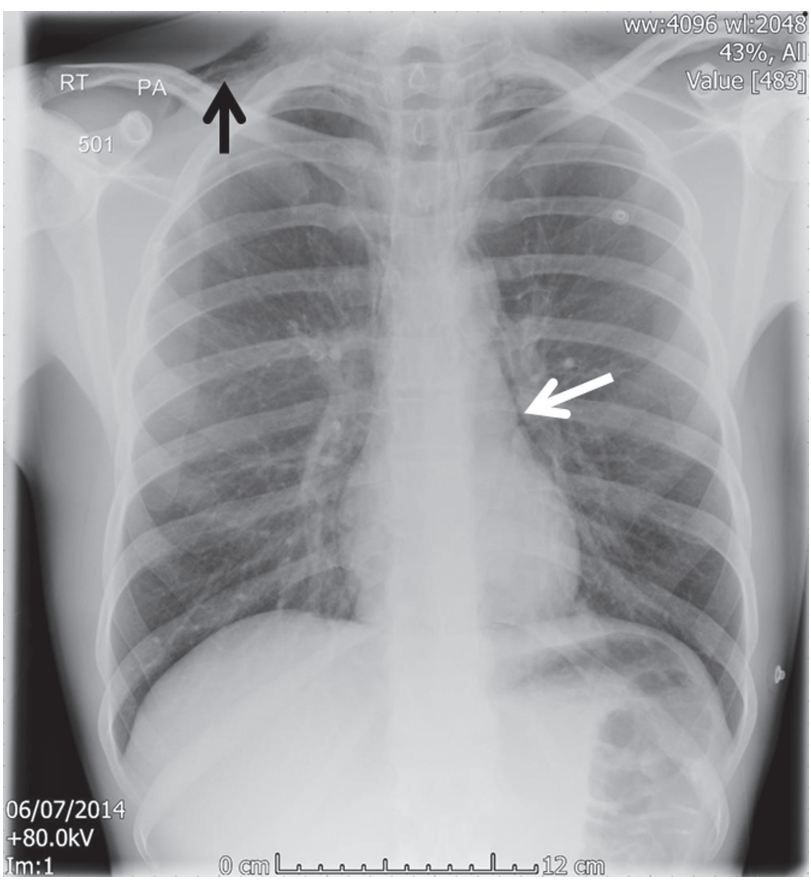

Fig 1. Admission chest X-ray.

A previously healthy 25-year-old male was admitted to the emergency department with severe chest pain soon after the consumption of 20 units of alcohol and snorting an unspecified amount of cocaine.

The chest pain was described as a central dull ache, radiating to the jaw and exacerbated by deep inspiration, eating and coughing. On examination, blood pressure was 118/68 with a regular pulse of $108 \mathrm{bpm}$. Oxygen saturations were $99 \%$ on air. Heart sounds were normal, jugular venous pressure was not raised and the chest was clear. The anterior chest wall was tender to palpation.

An electrocardiogram showed a sinus tachycardia, normal axis and no ischaemic changes. Blood tests on admission revealed an elevated troponin $\mathrm{T}$ of $44 \mathrm{ng} / \mathrm{L}$ (normal range, <14)

Authors: ${ }^{\text {A }}$ cardiology specialist trainee, Bristol Heart Institute, Bristol, UK; ${ }^{B}$ consultant cardiologist, Bristol Heart Institute, Bristol, UK; ${ }^{C}$ consultant cardiologist, Bristol Heart Institute, Bristol, UK

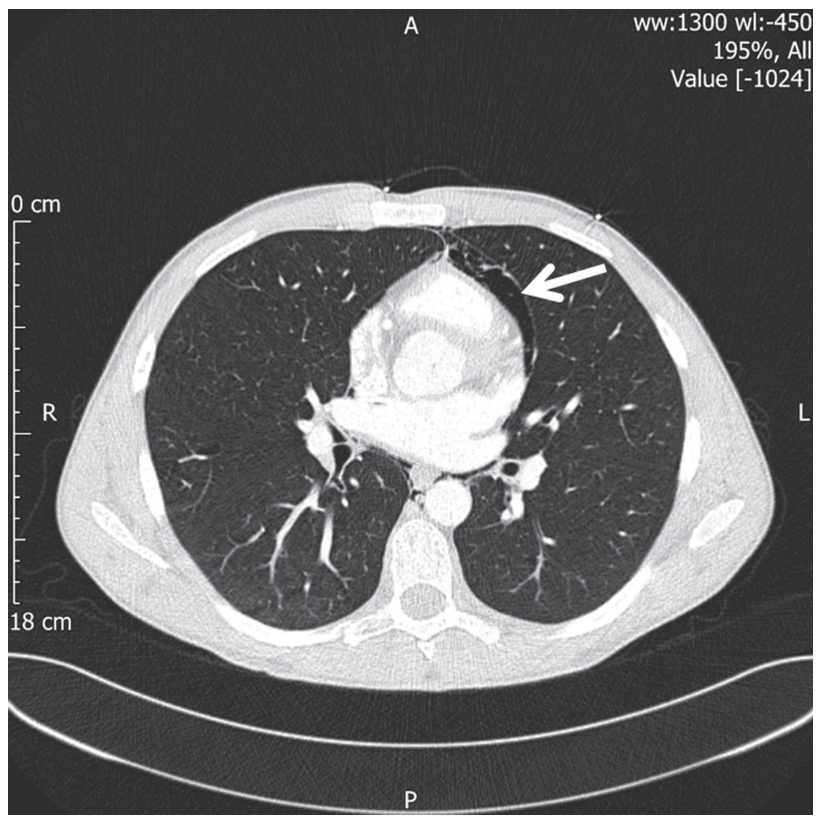

Fig 2. CT chest demonstrating pneumomediastinum.

(11 hours post-pain onset). He was referred to the cardiology team and a transthoracic echo demonstrated normal left ventricular systolic function and no regional wall motion abnormalities. The admission chest X-ray (Fig 1) demonstrated surgical emphysema in the right and left supraclavicular area (more obvious on the right) (black arrow) and a pneumomediastinum (white arrow). A computerised tomography chest scan confirmed these findings (Fig 2). Oral contrast did not show any leak from the oesophagus. Subsequent coronary angiogram demonstrated unobstructed coronary arteries. He was reviewed by the thoracic surgical team and treated conservatively. A follow-up chest X-ray two weeks later showed that the pneumomediastinum had resolved.

Chest pain following cocaine use is a common presenting symptom. ${ }^{1}$ The majority of patients are young, male, smokers and have a previous history of cocaine abuse. ${ }^{2}$ The differential diagnosis of cocaine-induced chest pain includes:

$>$ aortic dissection

$>$ coronary artery vasospasm

$>$ acute coronary syndrome

$>$ pulmonary haemorrhage 
$>$ pneumothorax

$>$ pneumopericardium

$>$ pneumomediastinum. $^{2}$

Pneumomediastinum is an uncommon complication of cocaine use and occurs more often when smoked rather than following nasal inhalation. ${ }^{3}$ It has been hypothesised that the forceful snorting and Valsalva manoeuvre increase the pressure in the alveoli which can cause alveolar rupture and pneumomediastinum. ${ }^{3,4}$ In addition the direct toxicity of the cocaine on the lung tissue may produce rupture. ${ }^{3,4}$ Cocaineinduced pneumomediastinum is a benign condition and symptoms usually subside after 24 hours. ${ }^{5}$

\section{References}

1 McCord J, Jneid H, Hollander JE et al. Management of cocaineassociated chest pain and myocardial infarction - a scientific statement from the american heart association acute cardiac care committee of the council on clinical cardiology. Circulation 2008;117:1897-907.

2 Restrepo CS, Carrillo JA, Martinez S et al. Pulmonary complications from cocaine and cocaine-based substances: imaging manifestations. Radiographics 2007;27:941-U913.

3 Kloss BT, Broton CE, Rodriguez E. Pneumomediastinum from nasal insufflation of cocaine. Int J Emerg Med 2010;3:435-7.

4 Gotway MB, Marder SR, Hanks DK et al. Thoracic complications of illicit drug use: an organ system approach. Radiographics 2002;22:S119-35.

5 Alnas M, Altayeh A, Zaman M. Clinical course and outcome of cocaine-induced pneumomediastinum. Am J Med Sci 2010;339:65-7.

Address for correspondence: Dr R Bond, Bristol Heart Institute, University Hospitals Bristol NHS trust, Bristol Royal Infirmary, Bristol BS2 8HW, UK.

Email: richard.bond@uhbristol.nhs.uk

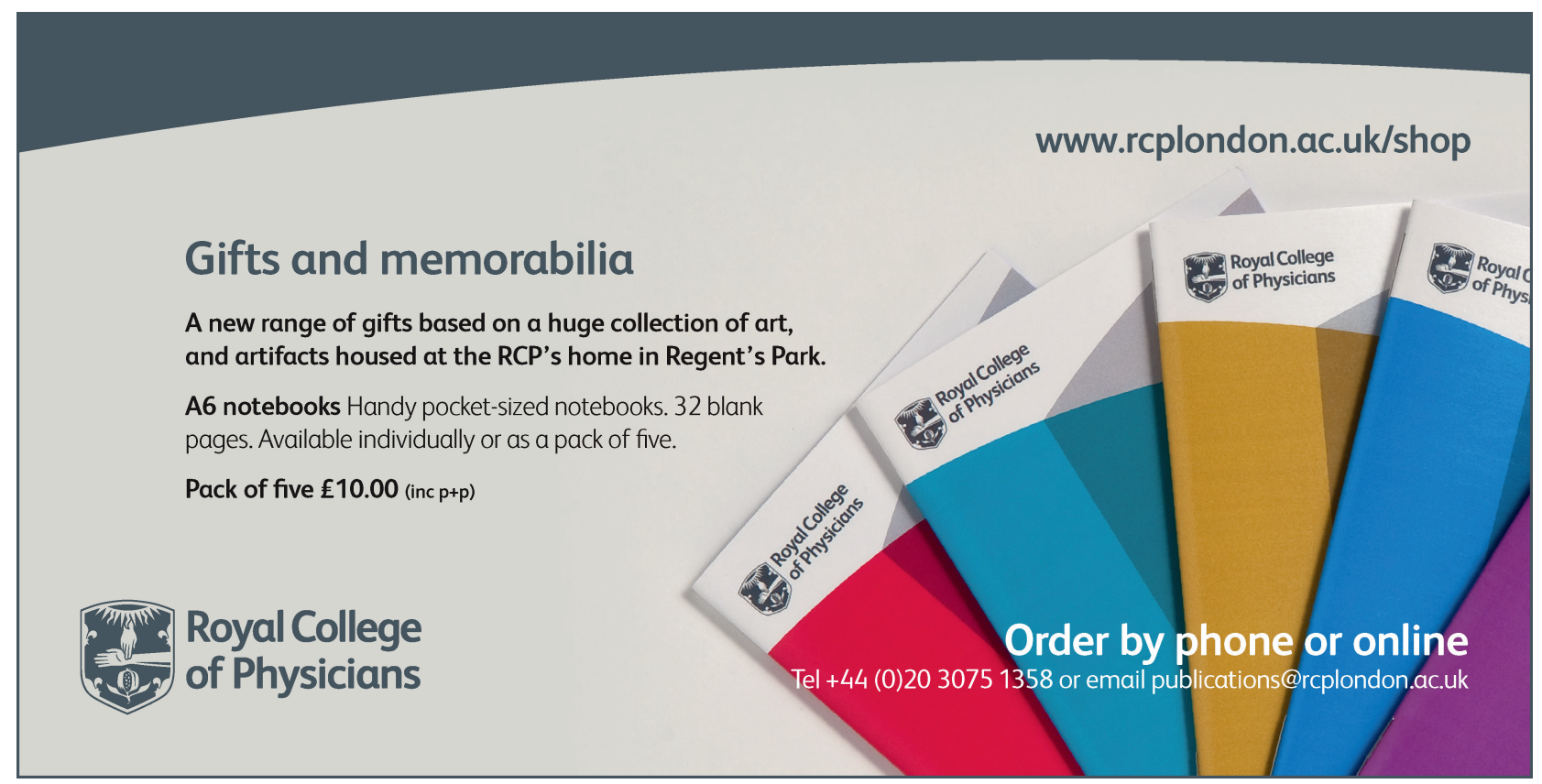

